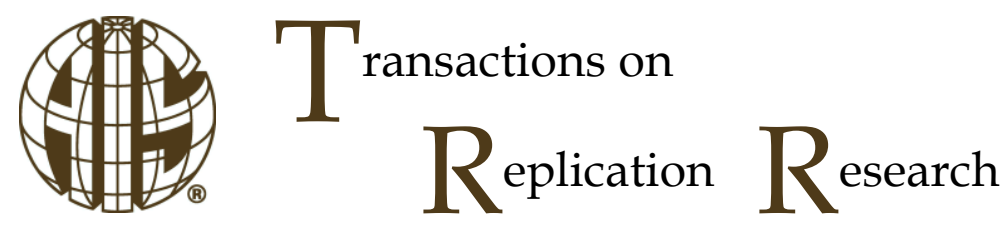

\title{
Maybe Waiting is Bad: A Replication Investigating Website Delay, Familiarity, and Breadth
}

Teresa M. Shaft

Division of Management Information Systems, University of Oklahoma

tshaft@ou.edu

\section{Dawei Wang}

Division of Management Information Systems, University of Oklahoma

dawei@ou.edu
Ling Zhu

Antra, Inc. Dulles, VA. zhuling9181@ou.edu

\section{Abstract:}

This study is an exact replication of an experiment investigating the impacts of website design on users' ability to use a website and their opinion of the website (Galletta et al., 2006). The replication confirms the importance of website design features, specifically delay, breadth, and familiarity on users' ability to use and form an opinion of a website. However, the replication did not confirm the main finding, that it is the interplay of these three variables, i.e., cognitive cost, that predict performance and attitude. The original study's findings indicate that the relationship between website design features and intention to use is fully mediated by attitude toward the website. However, the replication indicates that behavioral intentions are partially mediated by attitude toward the website. That our findings are somewhat inconsistent with those of the original study provides further support for the importance of replications.

Keywords: electronic commerce, response time, website design, performance 


\section{Introduction}

Online consumer spending in the United States had grown from 211 billion dollars in 2006 to over 805 billion in 2014 (Statista, 2016). Online shopping accounted for 2.2\% of total retail sales in 2005 (Galletta et al., 2006), but now accounts for approximately $8.9 \%$ of total retail sales (US Census Bureau, 2017) and is a world-wide phenomenon. For instance, China's online shopping market has grown from 128 billion yuan in 2008 to 5.2 trillion yuan (\$752 billion) in 2016 (Tong, 2017).

Website delay ("world wide wait") has been considered a barrier to successful "conversion" - turning a browsing experience into a purchase. Retailers have found that even small increases in speed can be associated with increases in revenue. Shopzilla improved page-loading time from 6 seconds to 1.2 and increased revenue by $12 \%$ (Čandrlić, 2012). Walmart found that each 1 second of improvement in page loading speed results in a $2 \%$ increase in conversions Čandrlić, G. (2012). Website delay continues to be an important factor for users and in turn web designers. Other factors also impact online shopping. The ease with which users find desired products also influences conversion. Users' ability to locate (forage for) information on the web, has been argued to be function of "information scent" (Pirolli and Card 1995). Information scent is the "imperfect" perception of the value, cost or access path of information sources obtained from proximal cues (Pirolli and Card 1995, p. 646). Consistent with this reasoning, Galletta et al. (2006) hypothesized and found that "providing a high degree of information scent through short delay, familiarity, and breadth" (p. 32) best supported users. Specifically, the interaction of website delay, product familiarity and breadth of choices influenced users' performance and attitude toward a website. Since the time of the original study, online purchases have grown substantially in volume and as a percentage of retail purchases. Therefore, understanding the factors that influence website usability remains relevant. Hence, replicating their study of how website delay, familiarity and breadth influence use of and attitude toward a website seems particularly germane.

Figure 1 shows the research model from the original study. The hypotheses investigated in this study are the same as the original study:

Hypothesis 1: When users perform search tasks, breadth and familiarity will undermine the negative effect of delay on user performance.

Hypothesis 2: When users perform search tasks, breadth and familiarity will undermine the negative effect of delay on behavioral intentions through attitudes.

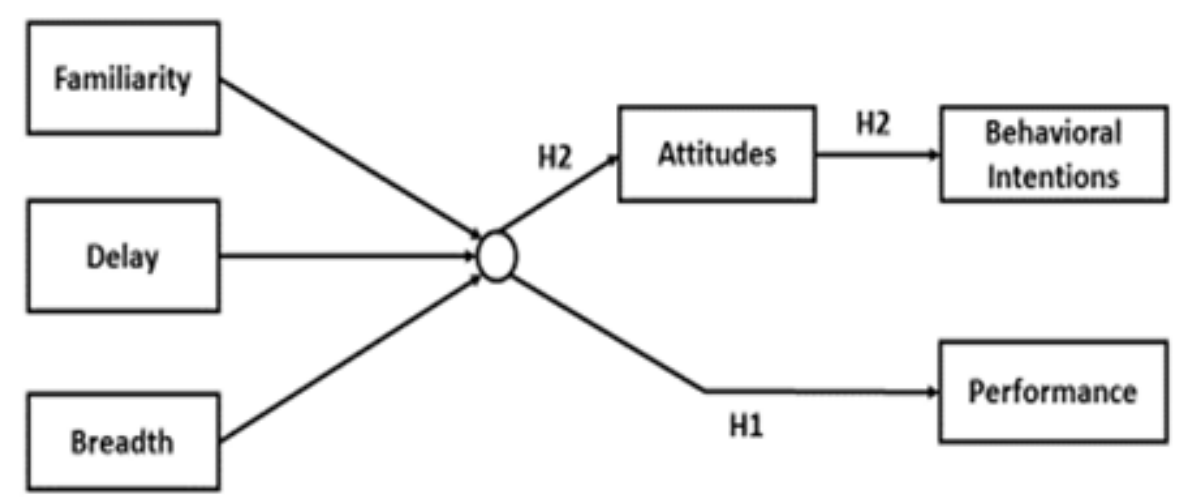

Figure 1. Research Model - Original Study

\section{Research Methodology}


Professor Galletta and his colleagues provided us with their experimental materials. Their generosity enabled us to conduct an exact replication. Therefore, we conducted an experiment with three independent variables (delay and depth, both treated as between-subjects factors, and familiarity, a within-subjects factor). The replication also used a counterbalanced, fully factorial design with 32 combinations of order, delay, breadth and familiarity.

\subsection{Operationalization of Variables}

Delay was manipulated by coding an eight-second delay per page for the slow condition and no delay for the fast condition. The manipulation check for the delay effect asked participants to rate the "speed of displaying each Web page" on a seven point Likert-style item. When using the "fast" site participants rated the speed as, on average, 5.9 (standard deviation 1.3). When using the "slow" site they rated the speed as 1.7 (standard deviation 1.3). The perceptions of average speed of displaying the web pages was statistically significantly different $(t=32.4$, one-tailed $p<0.0001)$. Thus, the manipulation of delay was effective. Note that the mean values appear similar to those reported by Galletta et al. (2006): 6.0 for the fast site and 2.2 for the slow. However, upon closer examination the responses for the slow condition - 2.2 (original) and 1.7 (replication) are different $(\mathrm{p}<.05)$. Hence, in the replication the slow condition was percieved as even slower than in the original study. The differences between the two studies seem reasonable given that individuals are likely to expect websites to respond more quickly now than when the original study was executed.

Familiarity was varied by creating two artificial websites. We used the same websites created by Galletta et al. (2006). The "familiar" site contained images, prices, and descriptions of products found in grocery and/or hardware stores. The "unfamiliar" site contained fictitious software products and accessories. The manipulation check for familiarity asked participants to "Evaluate your level of familiarity with the subject matter in the Web site". On average, participants rated the familiar site 5.4 (standard deviation 1.3) and unfamiliar site as 2.4 (standard deviation 1.4) on a seven-point Likert Scale. These averages are comparable to the original study, whose participants evaluated the "familiar" site 5.4 and the "unfamiliar" site 2.2. For the replication, the distinction between the two websites was statistically significant $(t=22.09$; one-tailed $p<0.001)$. Hence, the manipulation of familiarity was deemed effective.

Breadth was operationalized using the website structures provided by Galletta et al. (2006). Therefore, one website presented three options per page while the other contained nine. We assessed the effectiveness of the breadth manipulation using Galletta et al.'s (2006) item. Our manipulation check for breadth failed $(\mathrm{t}=.56$; one-tailed $\mathrm{p}>$.57). Galletta et al. (2006) report a similar issue. However, among their subjects, those who experienced the familiar website first, evaluated the site with more selections as broader than the site with fewer selections. It appeared that participants in both studies responded as if the differences in breadth were not perceived, despite websites that have obvious differences in the breadth of options (three options versus nine). Therefore, we investigated this issue further.

Our concern was that the wording of the item to assess participants' perception of website breadth might have been unclear (see item 1 in Table 1). Therefore, we created two additional items (see items 2 and 3 , Table 1) and used the same anchors as used in the original study (see again Table 1). We collected data from forty additional participants recruited from the same subject pool as the main study. As we focused on breadth in this additional check, we did not vary delay. Therefore, these participants experienced the nodelay condition; only familiarity and breadth varied. Using the original item plus the new items, we created a scale $(\alpha=.69$.) and computed a score by averaging subjects responses across the three items. When we compared responses across the breadth conditions we detected a statistically significant difference $(\mathrm{t}=2.08$, $\mathrm{df}=78, \mathrm{p}=.04$ ). Hence, it appears that the manipulation was effective but that the original single-item manipulation check was an insufficient measure. Therefore, we include breadth as a factor in our subsequent analyses of the main data.

\begin{tabular}{|l|l|l|}
\hline \multicolumn{2}{|c|}{ Table 1. Items Used to Assess Breadth } \\
\hline \multicolumn{2}{|c|}{ Anchors } \\
\hline 1. Number of further choices or links on each page/menu you visited. & $\begin{array}{l}\text { Extremely } \\
\text { Low/Little/ }\end{array}$ & $\begin{array}{l}\text { Extremely } \\
\text { High/Many }\end{array}$ \\
\cline { 1 - 1 } 2. The number of options on each page/menu. & \\
\cline { 1 - 1 } 3. The number of choices on each page/menu you visited. & \\
\hline
\end{tabular}


We recorded the number of clicks for each treatment cell (see Table 2). Our data follow the general pattern predicted. We find, as did the original study, that performance is worse than expected on the familiar site and better than expected on the unfamiliar site.

\begin{tabular}{|c|c|c|c|c|c|c|c|c|}
\hline \multicolumn{7}{|c|}{ Table 2. Average vs. Predicted Clicks for Navigation to a Given Node Original (Org) and Replication } \\
(Rep)
\end{tabular}

\subsection{Dependent Variables}

Table 3 presents a summary of the scales for each instrument, reliabilities, and correlations among the three measured items.

\begin{tabular}{|c|c|c|c|c|c|c|c|}
\hline \multicolumn{7}{|c|}{ Table 3. Correlations among the Measured Variables in the Model } \\
\hline \multirow{2}{*}{$\begin{array}{c}\text { Dependent } \\
\text { Measure }\end{array}$} & Scales & \multicolumn{2}{c|}{ Attitudes } & \multicolumn{2}{c|}{ Performance } & \multicolumn{2}{c|}{ Behavioral Intention } \\
\cline { 3 - 8 } & Original & Replication & Original & Replication & Original & Replication \\
\hline Attitudes & $\begin{array}{c}\text { Seven 9-point } \\
\text { scales }\end{array}$ & $(0.95)$ & $(0.95)$ & & & & \\
\hline Performance & $\begin{array}{c}\text { Nine binary } \\
\text { items }\end{array}$ & $0.495^{\star * *}$ & $0.289^{* * *}$ & $(0.90)$ & $(0.78)$ & & \\
\hline $\begin{array}{c}\text { Behavioral } \\
\text { Intentions }\end{array}$ & $\begin{array}{c}\text { Two 7-point } \\
\text { scale }\end{array}$ & $0.774^{* * *}$ & $0.807^{* * *}$ & $0.392^{* * *}$ & $0.262^{* * *}$ & $(0.94)$ & $(0.93)$ \\
\hline
\end{tabular}

Notes: Reliabilities are in the parentheses.

${ }^{* * *} \mathrm{p}<0.001$

Attitudes toward the site were measured by averaging the responses to the seven, nine-point Likert-type questions provided by Galletta et al. (2006). Cronbach's alpha was 0.95 , identical to that reported in the original study.

Performance was operationalized by averaging the number of search tasks accomplished by each participant for each website. The Kuder-Richardson-20 test, used to assess internal consistency for scales with dichotomous items, was 0.78 . Although lower than the .90 reported in the original study, it is acceptable for a nine- item questionnaire.

Behavioral Intentions were measured by computing the average of two items (How readily would you recommend that others visit this site?; How likely is it that you would want to visit this site again?) using seven point Likert-style scales. Cronbach's alpha was 0.93 , nearly identical to the .94 observed in the original study.

\subsection{Subjects}

We recruited 277 undergraduate business students from a MIS course at a large mid-western U.S. university. Sixteen of these students participated in a pilot study that allowed us to familiarize ourselves with the experimental procedures. For the main study, 261 undergraduate students (164 males, 96 females, 1 
unidentifiable) with average age of 20.03 years served as subjects. All participants were awarded extra credit points for participating in the study. Subjects from the pilot study were excluded from the data analysis. Our subject profile is comparable to that of the original study except that our subjects were enrolled in a lower-division business course, and the original relied upon subjects in an upper-division course. We eliminated fifteen observations due to missing data. To be consistent with the original study, we created a sample with an equal number of participants for each condition by randomly eliminating subjects so that our main analysis was based on 192 subjects.

Consistent with the original study, we randomly assigned students to one of 32 counterbalanced treatment conditions. We conducted a series of ANOVAs to test for differences across the cells on gender, computer efficacy, and computer experience. None of these ANOVAs were statistically significant. Hence, there appear to be no differences with regard to gender, computer efficacy, or computer experience between participants in the experimental conditions.

\subsection{Procedure}

The websites were created with 32 combinations. The contents were downloaded to each computer in the lab prior to the start of the experiment. Upon arrival, participants were provided a packet containing an informed consent form and the questionnaires pertaining to the experiment. The first author gave a short announcement describing the experimental procedures, and asked participants to sign the informed consent. If they were willing to proceed (all were), they began the experiment by completing the "warm-up" task ${ }^{1}$. Once that was complete, the screen displayed the numbers 1-32. The participant selected the number matching that on their packet of experimental materials, which sent him or her to the correct experimental treatment.

Subjects were prompted to complete nine tasks (i.e., locate information about nine different items) on each of the two experimental sites (familiar and unfamiliar). Subjects were asked to write their answers down for each task on the provided materials. We evaluated correctness by comparing each answer to the correct answer for that website. As participants worked, the actual number of clicks was recorded in the background. After answering questions about a particular site, participants were asked to close the browser window and complete questionnaires about attitude and behavioral intentions. Then, subjects were directed to the second website and repeated the process of finding items and answering questions about attitude and behavioral intentions. After finishing both sites, participants were asked to respond to items about computer efficacy and computer experience as well as provide some demographic information. At least one author stayed in the laboratory throughout the experiment to answer questions, should any arise, and collect the completed packets.

\section{Results}

As did the original study, we began our analysis with a multivariate ANOVA for attitudes and performance, followed by a univariate ANOVA for each dependent variable. We used SAS version 9.4. Descriptive statistics for performance and attitude are presented in Table 4. The results of our MANOVA are presented in Table 5, which reports the F-values for the Wilks' Lambda test. Unlike Galletta et al. (2006), the predicted three-way interaction was not significant. All main effects and two of the two-way interactions were statistically significant (familiarity $x$ delay and familiarity $x$ breadth). Individual ANOVAs were run for both dependent variables. The amount of explained variance for attitudes was .456 (compared to .557 in the original study) and for performance .292 (compared to .498). With regard to performance, the main effects and two interactions (familiarity $x$ delay and familiarity $x$ breadth) are statistically significant. With respect to attitudes, only the main effects and one interaction (familiarity $x$ delay) are statistically significant.

\begin{tabular}{|c|c|c|c|c|c|}
\hline \multicolumn{6}{|c|}{ Table 4. Cell Means for Attitudes and Performance } \\
\hline ? & & Original & Replication & Original & Replication \\
\hline E & Treatment & \multicolumn{2}{|c|}{ Slow } & \multicolumn{2}{|c|}{ Fast } \\
\hline
\end{tabular}

\footnotetext{
${ }^{1}$ We made two changes to the products displayed on the warm up task website provided by Galletta et al. (2006). We changed the product "VCRs" to "DVD Players" and "VHS Tapes" to "DVD-RWs"
} 


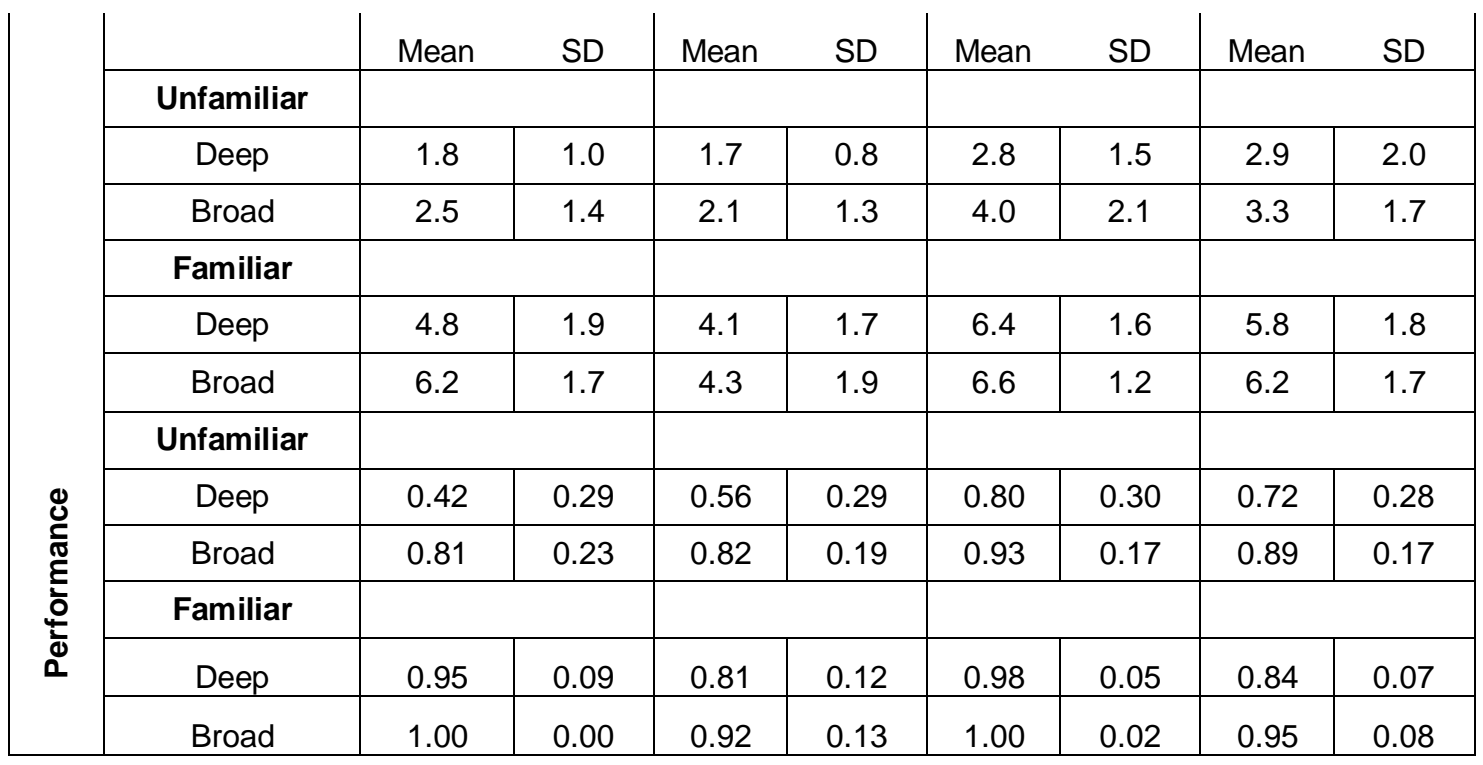

\begin{tabular}{|c|c|c|c|c|}
\hline \multirow{2}{*}{ Table 5. Overall MANOVA: Attitudes and Performance (Original Study and Replication Study } \\
\hline \multirow{2}{*}{ Factor } & \multicolumn{2}{|c|}{ F } & \multicolumn{2}{c|}{ Sig } \\
\cline { 2 - 5 } & Original & Replication & Original & Replication \\
\hline Delay & 37.3 & 44.0 & 0.000 & 0.000 \\
\hline Familiarity & 216.0 & 134.7 & 0.000 & 0.000 \\
\hline Breadth & 35.8 & 39.0 & 0.000 & 0.000 \\
\hline Delay*Familiarity & 17.2 & 4.1 & 0.000 & 0.018 \\
\hline Delay*Breadth & 6.4 & 0.8 & 0.002 & 0.435 \\
\hline Familiarity ${ }^{*}$ Breadth & 15.6 & 3.5 & 0.000 & 0.033 \\
\hline Delay*Familiarity ${ }^{*}$ Breadth & 7.7 & 1.1 & 0.001 & 0.321 \\
\hline
\end{tabular}

Next, we present the means across each treatment (Tables 6-8) for both dependent variables. We also report the tests for the main effects, which as Galletta et al. (2006) argued, may serve as another category of manipulation check. We find that the main effects for all treatments are statistically significant at $p<.05$.

\begin{tabular}{|c|c|c|c|c|c|c|c|c|c|c|}
\hline \multicolumn{11}{|c|}{ Table 6. Means Across the Delay Treatment (Original Study and Replication Study) } \\
\hline \multirow{3}{*}{$\begin{array}{c}\text { Dependent } \\
\text { measure }\end{array}$} & \multicolumn{4}{|c|}{ Slow } & \multicolumn{4}{|c|}{ Fast } & \multirow{2}{*}{\multicolumn{2}{|c|}{ Difference $(F, p)$}} \\
\hline & \multicolumn{2}{|c|}{ Mean } & \multicolumn{2}{|c|}{$\begin{array}{l}\text { Standard } \\
\text { deviation }\end{array}$} & \multicolumn{2}{|c|}{ Mean } & \multicolumn{2}{|c|}{$\begin{array}{l}\text { Standard } \\
\text { deviation }\end{array}$} & & \\
\hline & Org & Rep & Org & $\operatorname{Rep}$ & Org & $\operatorname{Rep}$ & Org & Rep & Org & Rep \\
\hline Attitudes & 3.8 & 3.0 & 2.3 & 1.9 & 5.0 & 4.5 & 2.3 & 2.3 & $\begin{array}{c}F=42.1 ; p< \\
0.001\end{array}$ & $\begin{array}{l}F=76.60 ; \\
p<0.001\end{array}$ \\
\hline Performance & 0.80 & 0.78 & 0.30 & 0.24 & 0.92 & 0.85 & 0.19 & 0.19 & $\begin{array}{l}F=40.8 \\
p<0.001\end{array}$ & $\begin{array}{l}F=14.85 \\
p<0.001\end{array}$ \\
\hline \multicolumn{11}{|c|}{ Table 7. Means Across the Breadth Treatment (Original Study and Replication Study) } \\
\hline & \multicolumn{4}{|c|}{ Deep } & \multicolumn{4}{|c|}{ Broad } & \multicolumn{2}{|c|}{ Difference $(F, p)$} \\
\hline
\end{tabular}




\begin{tabular}{|c|c|c|c|c|c|c|c|c|c|c|}
\hline \multirow{2}{*}{$\begin{array}{l}\text { Dependent } \\
\text { measure }\end{array}$} & \multicolumn{2}{|c|}{ Mean } & \multicolumn{2}{|c|}{$\begin{array}{l}\text { Standard } \\
\text { deviation }\end{array}$} & \multicolumn{2}{|c|}{ Mean } & \multicolumn{2}{|c|}{$\begin{array}{l}\text { Standard } \\
\text { deviation }\end{array}$} & \multirow[b]{2}{*}{ Org } & \multirow[b]{2}{*}{ Rep } \\
\hline & Org & Rep & Org & Rep & Org & Rep & Org & Rep & & \\
\hline Attitudes & 3.9 & 3.6 & 2.4 & 2.2 & 4.8 & 4.0 & 2.3 & 2.3 & $\begin{array}{l}F=27.3 \\
p<0.001\end{array}$ & $\begin{array}{l}F=4.29 \\
P<0.05\end{array}$ \\
\hline Performance & 0.79 & 0.73 & 0.31 & 0.24 & 0.93 & 0.90 & 0.16 & 0.16 & $\begin{array}{l}F=52.0 \\
p<0.001\end{array}$ & $\begin{array}{l}F=75.44 \\
p<0.001\end{array}$ \\
\hline \multicolumn{11}{|c|}{ Table 8. Means Across the Familiarity Treatment (Original Study and Replication Study) } \\
\hline \multirow{3}{*}{$\begin{array}{l}\text { Dependent } \\
\text { measure }\end{array}$} & \multicolumn{4}{|c|}{ Unfamiliar } & \multicolumn{4}{|c|}{ Familiar } & \multirow{2}{*}{\multicolumn{2}{|c|}{ Difference $(F, p)$}} \\
\hline & \multicolumn{2}{|c|}{ Mean } & \multicolumn{2}{|c|}{$\begin{array}{l}\text { Standard } \\
\text { deviation }\end{array}$} & \multicolumn{2}{|c|}{ Mean } & \multicolumn{2}{|c|}{$\begin{array}{l}\text { Standard } \\
\text { deviation }\end{array}$} & & \\
\hline & Org & Rep & Org & Rep & Org & Rep & Org & Rep & Org & Rep \\
\hline Attitudes & 2.8 & 2.5 & 1.7 & 1.7 & 6.0 & 5.1 & 1.8 & 2.0 & $\begin{array}{l}F=331.7 \\
p<0.001\end{array}$ & $\begin{array}{c}F=230.69 \\
p<0.001\end{array}$ \\
\hline Performance & 0.74 & 0.75 & 0.31 & 0.27 & 0.98 & 0.88 & 0.06 & 0.12 & $\begin{array}{l}F=144.0 \\
p<0.001\end{array}$ & $\begin{array}{l}F=49.48 \\
p<0.001\end{array}$ \\
\hline
\end{tabular}

Consistent with the original study, we conducted two tests to assess mediation of attitudes between the experimental factors and behavioral intentions. We first tested according to the approach recommended by Baron and Kenney (1986), then using PLS.

Following Baron and Kenney's (1986) approach, we evaluate if the relationship between cognitive cost and behavioral intentions is mediated by attitude by establishing four things (see Table 9): that (a) cognitive cost (as operationalized by the experimental factors: delay, familiarity and breadth) and attitude are correlated, which was confirmed; (b) cognitive cost affects behavioral intention in a regression of the experimental factors on behavioral intentions, also confirmed; (c) the mediator - attitude - must affect the behavioral intention when regressing both the independent and mediator variables on the dependent variable, also confirmed. Note that percent of explained variance is higher than for the previous model; and (d) the effect of in the independent variables (the experimental factors) on the dependent variable in (c) must be less than in (b). This final criterion is also satisfied. Note that the t-values for all three experimental factors are lower than in steps a or b. In fact, the t-values associated with two of the factors (delay and breadth) are no longer statistically significant. Hence, based on this analysis it appears that attitudes mediate the relationship between the experimental factors and behavioral intentions. From Table 9, one can see that pattern of results is generally consistent with the original study².

\begin{tabular}{|c|c|c|c|c|c|c|}
\hline \multicolumn{7}{|c|}{ Table 9. Mediation Test Statistics } \\
\hline & \multicolumn{7}{|c|}{$\begin{array}{c}\text { Step (a): Regression of cost } \\
\text { on attitude }\end{array}$} & $\begin{array}{c}\text { Step (b): Regression of } \\
\text { experimental factors alone } \\
\text { on behavioral intention }\end{array}$ & $\begin{array}{c}\text { Step (c): Regression of } \\
\text { experimental factors plus } \\
\text { attitude on behavioral } \\
\text { intention }\end{array}$ \\
\cline { 2 - 7 } & Original & Replication & Original & Replication & Original & Replication \\
\hline $\begin{array}{c}\text { Adjusted R2 } \\
\text { (overall) }\end{array}$ & 0.564 & 0.280 & 0.396 & 0.389 & 0.571 & 0.672 \\
\hline \multicolumn{2}{|c|}{ Coefficients for experimental factors for Steps (b) and (c): } & \\
\hline - Delay $t$ value & & & $3.2^{* * *}$ & $-11.76^{* * *}$ & $2.5^{* * *}$ & -1.49 \\
\hline \multirow{2}{*}{$\begin{array}{c}\text { - Familiarity } t \\
\text { value }\end{array}$} & & & $13.0^{* * *}$ & $-10.19^{* * *}$ & $2.4^{* * *}$ & $-5.24^{* * *}$ \\
\hline
\end{tabular}

\footnotetext{
${ }^{2}$ Note that the adjusted R-squared for step (a) increases to .45 when the experimental factors are included in the model rather than the cognitive cost variable computed from the experimental factors.
} 
To examine the relationship between the experimental factors, attitudes and behavioral intention further, we conducted a partial-least squares analysis using SmartPLS 3.0. As did the original study, we created a single-variable (cognitive cost) by multiplying the levels of each experimental condition such that the levels expected to create the least cognitive effort (fast, familiar, and broad) were assigned a "1" and the more cognitively difficult, "costly," conditions (slow, unfamiliar, and deep) were assigned a "2". Multiplying the levels converts the experimental factors to a single value representing cognitive cost.

Figures 2 and 3 depicts the path coefficients and significance levels from the original study $(O)$ with the replication (R). These figures highlight the one difference between the replication and original PLS results. Specifically, the path from cognitive cost to behavioral intention is statistically significant in the replication (note that this path was included but not hypothesized in the original study, hence our use of a dashed line in the model). Note, however, that this path is weaker than the other paths. Further, consistent with the original study, when compared to the direct effects model, the mediated model explains more variance in behavioral intentions and the explained variance for performance is nearly the same.

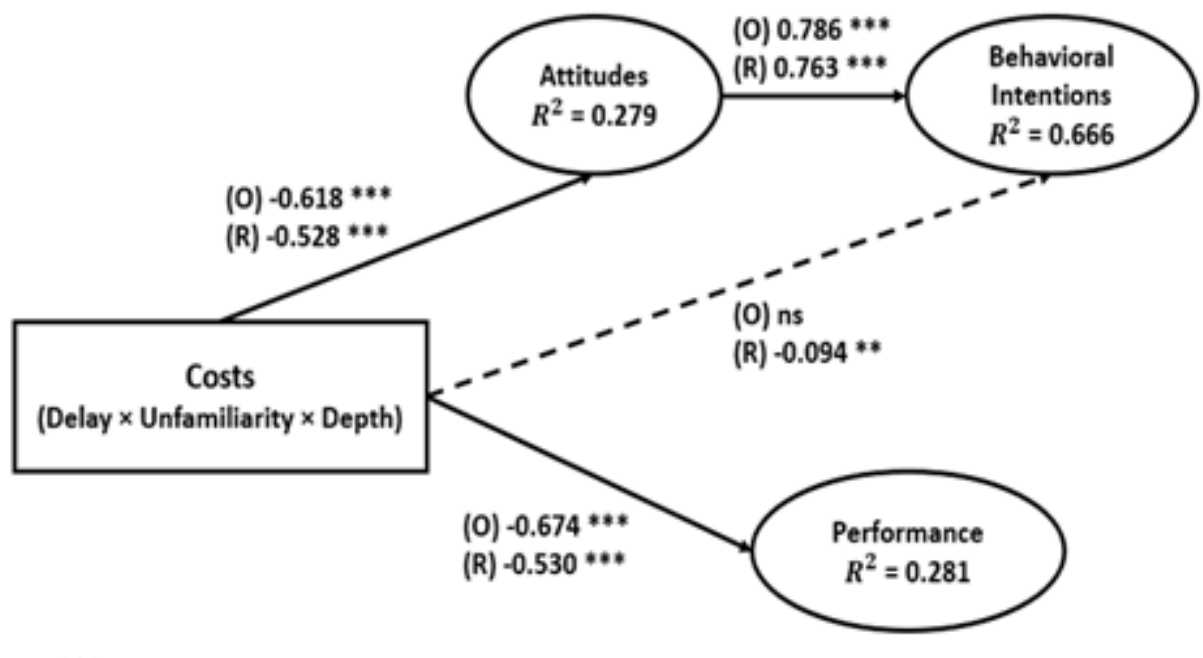

*** $p<0.001$

Figure 2. PLS Model with Hypothesized Paths and Additional Path

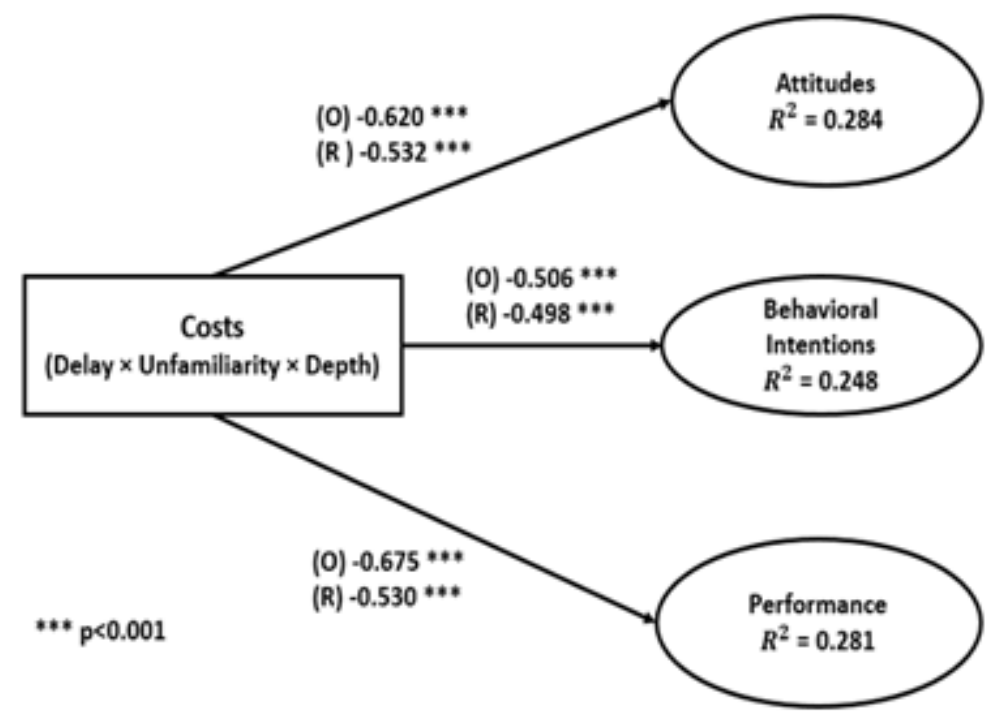

Figure 3. PLS Model without Attitudes as a Mediator 
For comparison purposes, we provide graphical depictions of the impact of the three experimental variables on attitude and performance for our data (Figures 4 and 6) and the original study (Figures 5 and 7). Note that despite that non-significant three-way interaction, the replication results reflect a pattern similar to that of the original study ${ }^{3}$. The lowest levels for performance and attitude occur when searching unfamiliar items, using a deep menu structure, while experiencing a delay. The highest performance and attitudes occur when searching for familiar items on a web site with a broad structure and no delay. Although the replication study did not detect a statistically significant interaction of the three experimental factors, recall that familiarity was part of both statistically significant two-way interactions. However, when we compare the F ratios in the same fashion as the original study, the impact on performance of familiarity compared to breadth is .66 (49.48/75.44), and was 2.8 in the original study. With regard to attitude, the ratio is $53.8(230.69 / 4.29)$, even higher than the 12.1 ratio reported for the original study. Hence, the impact of familiarity influenced attitude more than breadth, but breadth impacted performance more than familiarity ${ }^{4}$. Note that the effect of familiarity was consistently stronger than that of delay: $3.3(49.48 / 14.85)$ for performance and 3.0 (230.69/76.60) for attitude. The original study noted that familiarity dampened the ill effects of delay. Our study supports the importance of familiarity particularly with regard to the ability of familiarity to help users overcome the negative effects of a slow website.

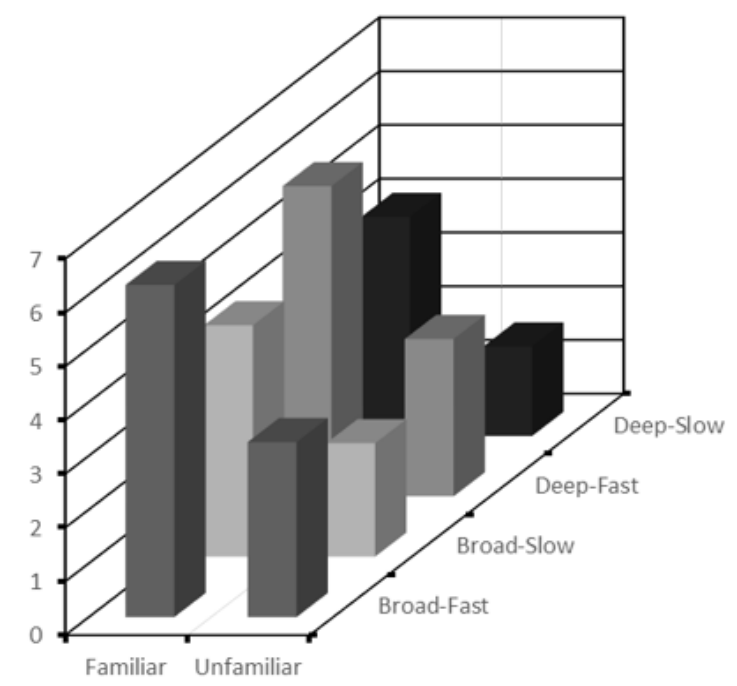

Figure 4. Three-Way Interaction for Attitude (Replication Study)

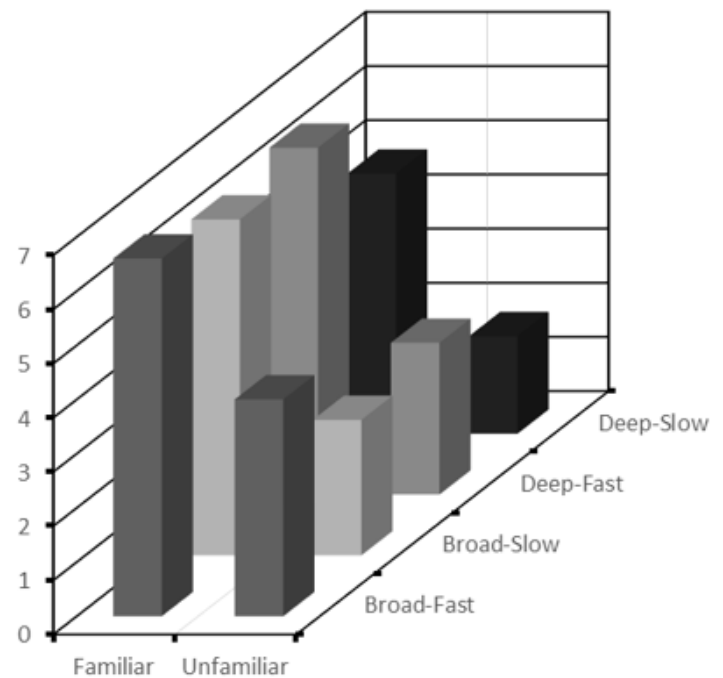

Figure 5. Three-Way Interaction for Attitude (Original Study)

\footnotetext{
${ }^{3}$ Based on a visual examination of the results, it may appear that the three way interaction of delay ${ }^{*}$ breadth ${ }^{\star}$ familiarity influences performance but was undetected when examined via the MANOVA. However, an ANOVA investigating performance fails to detect a statistically significant three-way interaction $(p=.14)$. Note when attitude is examined independently, the interaction is weaker $(p=.67)$. ${ }^{4}$ Consistent with Galletta et al. (2006) these calculations use the F-ratios reported in Tables 8 and 9.
} 


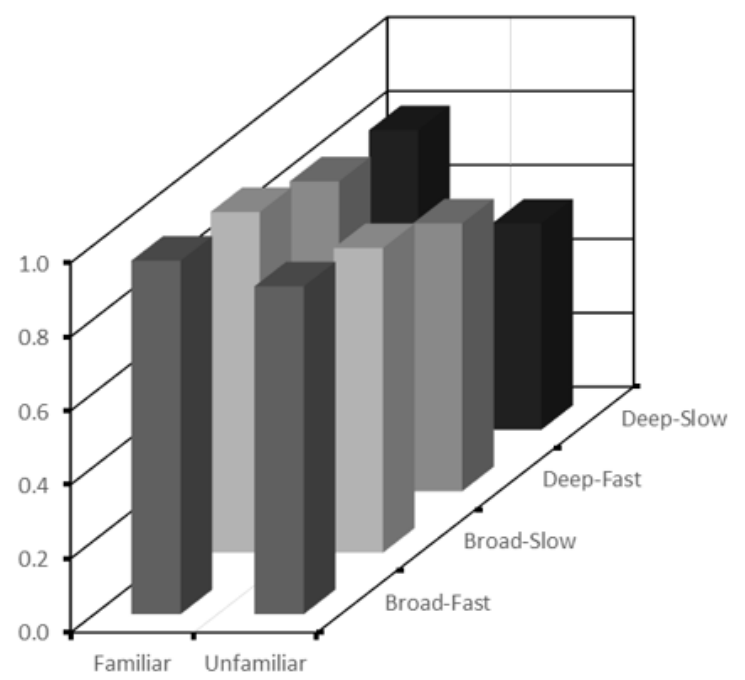

Figure 6. Three-Way Interaction for Performance (Replication Study)

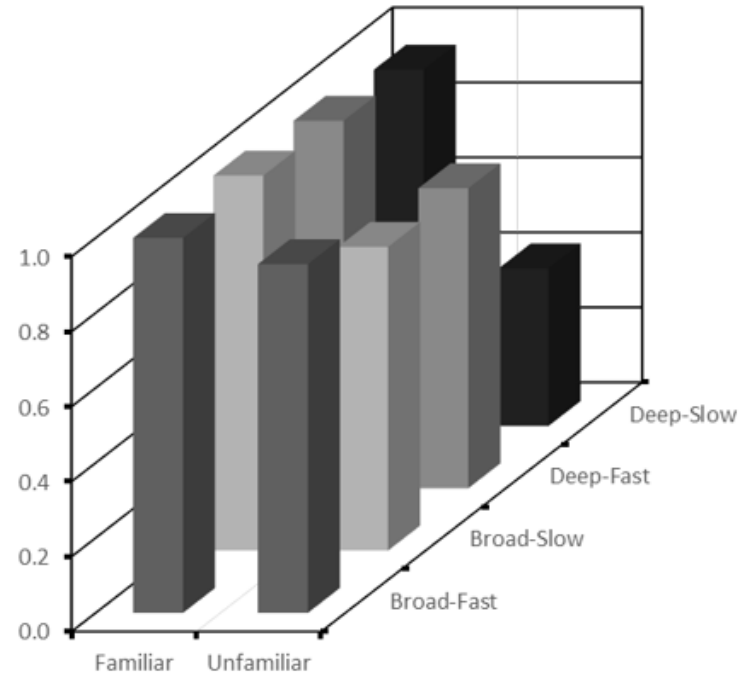

Figure 7. Three-Way Interaction for Performance (Original Study)

\section{Discussion}

This study achieves the goal of the replication by examining the impact of website features - delay, breath, and familiarity - on users' attitudes, behavioral intentions, and performance. In the original study, cognitive cost was operationalized as the interaction of delay, breadth, and familiarity, which predicted attitudes and task performance. However, the replication failed to detect a statistically significant effect due to the interaction of these factors on the dependent variables. In the replication, the main effects for each experimental factor as well as the interactions of delay and familiarity plus familiarity and breadth were statistically significant.

With regard to the nature of the relationship between cognitive cost and behavioral intentions, both the original and replication studies support the argument that attitude mediates their relationship. However, unlike the original study, the replication detected an additional statistically significant path: the direct path from cognitive cost to behavioral intentions. In the original study, this un-hypothesized path was included in the PLS analysis but was not significant. Thus, the results of the replication are more ambiguous than the original study. It appears that the relationship between cognitive cost and behavioral intentions may not be fully mediated by attitude. At the time of the original study, the dominant theorizing was that attitude fully mediated the influence between various technology factors and behavioral intentions. More recent studies have found that attitude does not always fully mediate intentions (e.g., Kim, Chun, \& Song, 2009; Liang, Ekinci, Occhiocupo, \& Whyatt, 2013). For instance, attitudes towards electronic word-of-mouth (eWOM) communication partially mediates the effects of adoption of electronic communication technology on intention to use eWOM communication media (Liang et al. 2013). Consistent with some more recent studies, our replication indicates that design characteristics can exhibit direct impacts on behavioral intentions. This possible evolution in the nature of the relationship between attitudes and behavioral intentions provides further rationale for replications as some behavioral patterns may be fluid over time. Future studies should continue to investigate the nature of the relationship between web site design factors, attitudes towards a web site, and behavioral intentions of web site usage.

We also note that both the original and replication studies experienced difficulty assessing perceptions of breadth (i.e., the number of choices on a webpage). We found that a single-item was ineffective at assessing participants' perceptions. We encourage other researchers to consider multiple items to assess the effectiveness of manipulations. There are trade-offs between single- and multiple-item approaches to measurement: multiple items contribute to participant fatigue, increase the cost of data collection, etc. (Diamantopoulos et al., 2012). A single-item can be effective in some situations, such as the checks on delay and familiarity. Single items are generally preferred when sample sizes are small (less than 50 ) or 
inter-item correlations between items are quite high (Diamatopoulos et al., 2012). Further, some have advocated for single-items measures of concrete attributes (Rossiter, 2002). Based on our and Galletta et al.'s (2006) difficulty assessing perceptions of differences in breadth, it may be that breadth is not a concrete attribute, whereas familiarity and delay are. Hence, multiple items may be appropriate to assess perceptions of website breadth.

We also note that similar to Galletta et al. (2006), participants perceived the pages containing unfamiliar products as broader than pages presenting familiar products, regardless of the number of choices on a webpage. This is not entirely surprising as working in an unfamiliar domain is more difficult than a familiar domain (Shaft and Vessey, 1995). Hence, although our findings with regard to familiarity are not as strong as those of the original study, our findings support the idea that user interface designers should consider users' levels of familiarity with the content area when designing interfaces.

\section{Conclusion}

The objective of this study was to confirm the findings reported by Galletta et al. (2006). Although this replication confirmed the importance of the design factors (domain familiarity, breadth of choices, and website delay) identified by Galletta et al. (2006), we were unable to replicate the interaction of these factors (cognitive cost) as the ultimate influence on website performance and attitudes toward the website. The other notable difference between our findings and those of the original study is that the relationship between cognitive cost and behavioral intentions may be partially, rather than fully, mediated by attitude toward the website.

The somewhat inconsistent findings between the original and replication are notable given that this is an exact replication, using the materials kindly provided by the original authors and a subject-pool consistent with that of the original study. Such a scenario would seem most likely to confirm original findings. That the replication failed to confirm completely the original findings supports the importance of replications.

\section{Acknowledgements}

We wish to thank Dennis Galletta, Raymond Henry, Scott McCoy and Peter Polak, the authors of the original paper, for providing us with their experimental materials and answering our many questions as we replicated their study.

\section{References}

Baron, R. M., \& Kenny, D. A. (1986). The moderator-mediator variable distinction in social psychological research: Conceptual, strategic, and statistical considerations. Journal of Personality and Social Psychology, 51(6), 1173-1182.

Čandrlić, G. (2012). How Website Speed Affects Conversion Rates. Retrieved from http://www.globaldots.com/how-website-speed-affects-conversion-rates/.

Diamantopoulos, A., Fuchs, C., Wilczynski, P., \& Kaiser, S. (2012). Guidelines for choosing between multiitem and single-item scales for construct measurement: A predictive validity perspective. Journal of the Academy of Marketing Science, 40(3), 434-449.

Galletta, D. F., Henry, R. M., McCoy, S., \& Polak, P. (2006). When the wait isn't so bad: The interacting effects of website delay, familiarity, and breadth. Information Systems Research, 17(1), 20-37.

Kim, Y. J., Chun, J. U., \& Song, J. (2009). Investigating the role of attitude in technology acceptance from an attitude strength perspective. International Journal of Information Management, 29(1), 67-77.

Liang, S. W., Ekinci, Y., Occhiocupo, N., \& Whyatt, G. (2013). Antecedents of travellers' electronic word-ofmouth communication. Journal of Marketing Management, 29(5-6), 584-606. 
Pirolli, P. and Card, S. (1999) Information Foraging. Psychological Review, 106(4), 643-675.

Rossiter, J. R. (2002). The C-OAR-SE procedure for scale development in marketing. International Journal of Research in Marketing, 19(4), 305-335.

Statista. (2016). B2C e-commerce volume in the United States from 2006 to 2014 (in billion U.S. dollars). Retrieved from http://www. statista.com/statistics/239372/us-b2c-e-commerce-volume-since-2006/.

Tong, F. (2017). Online shopping in China grows $26.2 \%$ in 2016 . Retrieved from https://www.digitalcommerce360.com/2017/02/06/online-shopping-china-grows-262-2016/

US Census Bureau. (2017) Quarterly Retail E-Commerce Sales $2^{\text {nd }}$ Quarter 2017. Retrieved from https://www2.census.gov/retail/releases/historical/ecomm/17q2.pdf. 


\begin{abstract}
About the Authors
Teresa Shaft is an Associate Professor of Management Information Systems at the University of Oklahoma. She received her Ph.D. from The Pennsylvania State University. Her research interests include the cognitive processes used by IS professionals during system development and maintenance, the role of IS in environmental management and obtaining value from IT investments. Her work has been published in Information Systems Research, Management Information Systems Quarterly, Journal of the Association of Information Systems, Journal of Management Information Systems, Association for Information Systems Transactions on Human-Computer Interaction, Business and Society, Database Advances, and Journal of Industrial Ecology. She is a co-founder and current president of IS-CORE, a special interest group of AIS. Her research has been supported by grants from the National Science Foundation.
\end{abstract}

Dawei Wang is a doctoral candidate in the Division of Management Information Systems at the University of Oklahoma. He holds a bachelor degree in Automation from the Beijing Institute of Technology, and an MBA from the University of Delaware. His research interests include IT diffusion and compliance with information security policies. He has presented research at the International Conference on Information Systems, The Academy of Management, and the Big XII+ MIS Research Symposium.

Ling Zhu received his M.S. in Management of Information Technology from the Division of MIS, Michael F. Price College of Business, The University of Oklahoma. He works as full-stack software engineer at Antra, Inc. His research focuses on requirement engineering, text analysis, and how information technology such as business intelligence, facilitates the improvement of employee performance. He has presented research at Big XII+ MIS Research Symposium, and published in the Computer Science Journal (China).

Copyright $@ 2018$ by the Association for Information Systems. Permission to make digital or hard copies of all or part of this work for personal or classroom use is granted without fee provided that copies are not made or distributed for profit or commercial advantage and that copies bear this notice and full citation on the first page. Copyright for components of this work owned by others than the Association for Information Systems must be honored. Abstracting with credit is permitted. To copy otherwise, to republish, to post on servers, or to redistribute to lists requires prior specific permission and/or fee. Request permission to publish from: AIS Administrative Office, P.O. Box 2712 Atlanta, GA, 30301-2712 Attn: Reprints or via e-mail from ais@aisnet.org. 